Article

\title{
Cost Analysis of Chaff Harvesting Concepts in Germany
}

\author{
Jannike Sophie Unger and Christoph Glasner *(i)
}

Fraunhofer Institute for Environmental, Safety, and Energy Technology UMSICHT, Osterfelder Str. 3, 46047 Oberhausen, Germany; jannike-sophie.unger@umsicht.fraunhofer.de

* Correspondence: christoph.glasner@umsicht.fraunhofer.de; Tel.: +49-208-8598-1133

Received: 25 June 2019; Accepted: 20 September 2019; Published: 25 September 2019

\begin{abstract}
This work assesses the costs of exploiting the biomass feedstock chaff. Chaff is a harvest residue generated during the conventional grain harvesting process and usually remains on the field. In this paper, the costs of collecting and supplying chaff to the end user with different harvesting methods and supply chains are analyzed. The costs are estimated for a base case defining a set of general assumptions. The impact of these assumptions is analyzed in a sensitivity analysis by means of tornado diagrams. A full costing method based on the VDI guideline 2067 part 1 is applied for the cost estimation. The cost analysis reveals that ceasing the fractioning of grain, straw and chaff during harvesting and transporting them as a mixture reduces the harvesting costs significantly. The costs are decreased due to a reduction in agricultural operations and processing large amounts of material. The lowest total costs originate from the production of chaff-straw bales. Harvesting chaff as a single fraction leads to the highest costs with the investigated supply chains. Comparing the costs of chaff supply to potential revenues shows that an exploitation of the harvest residue can be economically feasible.
\end{abstract}

Keywords: harvest residues; chaff; cost estimation; harvesting methods; compact harvest; biomass supply chains; herbaceous biomass; pelleting costs

\section{Introduction}

\subsection{Problem Definition}

The global energy demand increases while at the same time fossil fuels deplete. Despite the need to access renewable energy sources, the utilization of biomass for energetic purposes is in critique due to the competition with food cultivation. The energetic application of residues is one approach to tackle this dilemma [1-4]. The utilization of agricultural residues is promoted at EU level by the "double counting mechanism". In order to fulfill the European biofuel blending quota, biofuels from residues are counted twice [5]. Exploiting the harvest fraction chaff is one way of increasing the energetic utilization of agricultural residues by accessing a so far unused biomass feedstock.

In the conventional grain harvesting process, a combine harvester separates the harvested biomass into grain, straw and chaff. The harvesting machine transfers grain into its corn tank and usually places straw in a swath for subsequent baling and collection. The remaining non-grain material, chaff, is disposed of by blowing it widely onto the field [6]. In Europe, there is currently no established practice to collect chaff during harvesting. However, a collection and removal of chaff represents a herbicide-free weed management technique, as chaff contains most of the harvested weed seeds [7]. Chaff collection can prevent the weed seeds from entering the soil and reduce the spread of weed patches [8]. This is important due to an increasing number of herbicide resistant weed species and restricted agrochemicals causing a major problem in agriculture $[9,10]$. 
The annual mass potential of wheat and spelt chaff is estimated to be $38 \times 10^{6}$ tons in the EU-28 [11]. An energetic utilization of chaff could contribute to a sustainable energy supply [12]. In addition, there are various potential pathways for a material utilization of chaff [13-16].

\subsection{Chaff Harvesting Concepts}

The transnational research project "Sweedhart" developed and investigated innovative harvesting concepts that aim for the collection and targeted handling of chaff. The Sweedhart project examined important aspects of the harvesting concepts in field tests and evaluated their weed reduction effect [7].

The costs of supplying chaff according to four different concepts are estimated in this study.

Instead of blowing chaff onto the field during harvesting, the concepts consider different techniques for the collection and targeted handling of chaff. For a sustainable use, the consumption must not exceed the sustainable removal rate. For all concepts, a sustainable removal rate for the total straw and chaff of $33 \%$ was assumed [1]. Considering average yields of 1.5 tons chaff and 8 tons straw per hectare, the entire chaff fraction and 1.64 tons straw can be collected without exceeding the sustainable removal rate [17].

Figure 1 gives an overview of the process steps of the examined concepts.

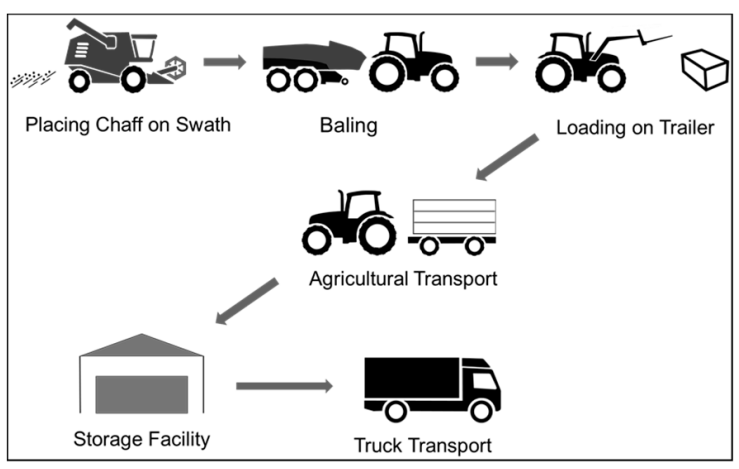

(A)

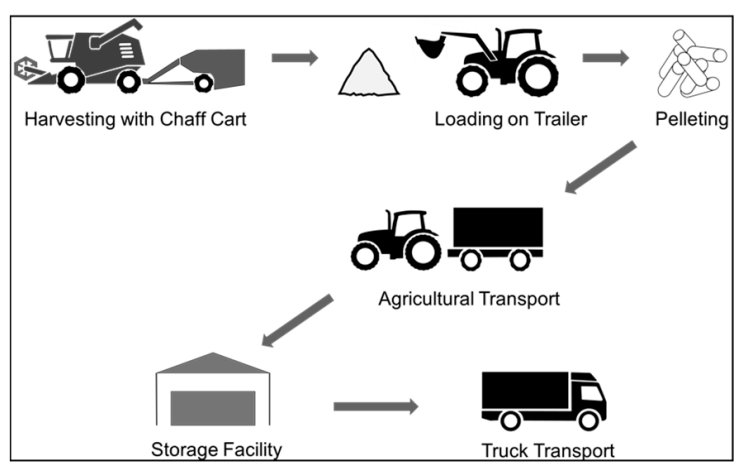

(C)

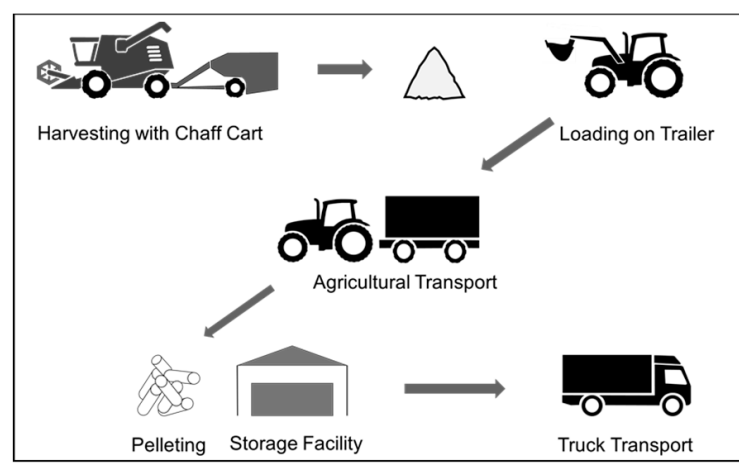

(B)

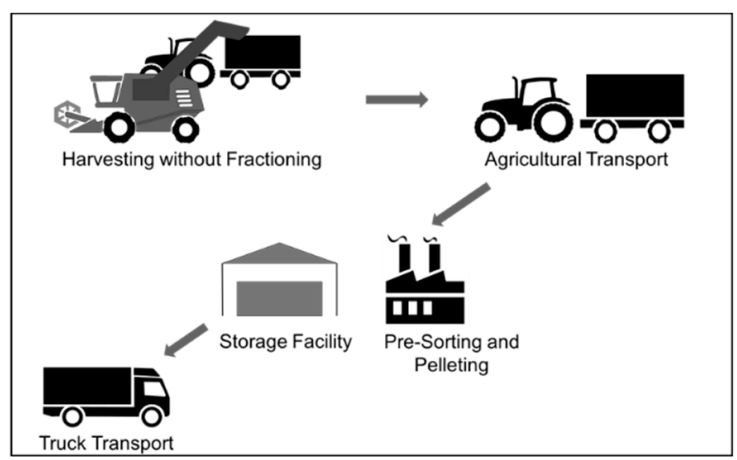

(D)

Figure 1. (A) Process chain Concept A (B) Process chain Concept B. (C) Process chain Concept C, (D) Process chain concept D.

\subsubsection{Concept A: Bales}

Concept A analyzes the costs of placing chaff on top of the straw swath to produce combined chaff-straw bales. After placing chaff on top of the straw swath, the entire swath is compressed into bales with a conventional bale press. The chaff-straw bales are subsequently loaded onto a trailer and transported to the storage facility. From the storage facility, the bales are transported to the end user by truck. Placing chaff on top of the straw swath during harvesting, requires an adaption of the conventional combine harvester. Due to this technical adjustment, a performance loss of the combine harvester was observed during field tests, which reduced the harvesting velocity. 


\subsubsection{Concept B and C: Chaff Piles and Pelleting}

Concept B and C examine the costs of collecting chaff as a single fraction. During harvesting, loose chaff is collected by using a chaff cart. The application of chaff carts is an established weed management technique in Australia. The chaff cart is pulled by a combine harvester, which is adjusted similarly to Concept A. The chaff cart unloads the material periodically producing chaff piles, which are afterwards loaded onto a trailer by a tractor. Both concepts consider producing chaff pellets in a decentralized conditioning process at the farm (Concept $B$ ) or at the field side (Concept $C$ ). The pellets are stored and transported to the end user by truck.

\subsubsection{Concept D: Compact Harvest and Pelleting}

Concept D, which is based on the compact harvest principle [18,19], analyzes the costs of harvesting without fractioning by using a new combine harvester, the "compact harvester". The compact harvester does not separate grain, straw and chaff during harvesting. Instead, the three fractions are mixed and conveyed onto a trailer. The trailer is transported to a central conditioning plant where the mixture is sorted and chaff subsequently pelleted and stored. From the storage facility, the chaff pellets are transported to the end user by truck.

This study analyzes the costs of supplying chaff to the end user based on the four harvesting concepts developed by Sweedhart. The analysis identifies the most cost-efficient harvesting concept and derives important framework conditions for the implementation.

\section{Materials and Methods}

\subsection{Framework and Biomass Supply Chains}

The biomass supply chain provides the framework for the calculation of the total chaff supply cost. All costs along the biomass supply chain with the steps harvesting, agricultural transport, conditioning, storage and further transport are included in the calculation. Figure 2 depicts the analyzed supply chains for each concept. Concept B, C and D include a pelleting process with a drying, a size reduction and a pelleting operation.

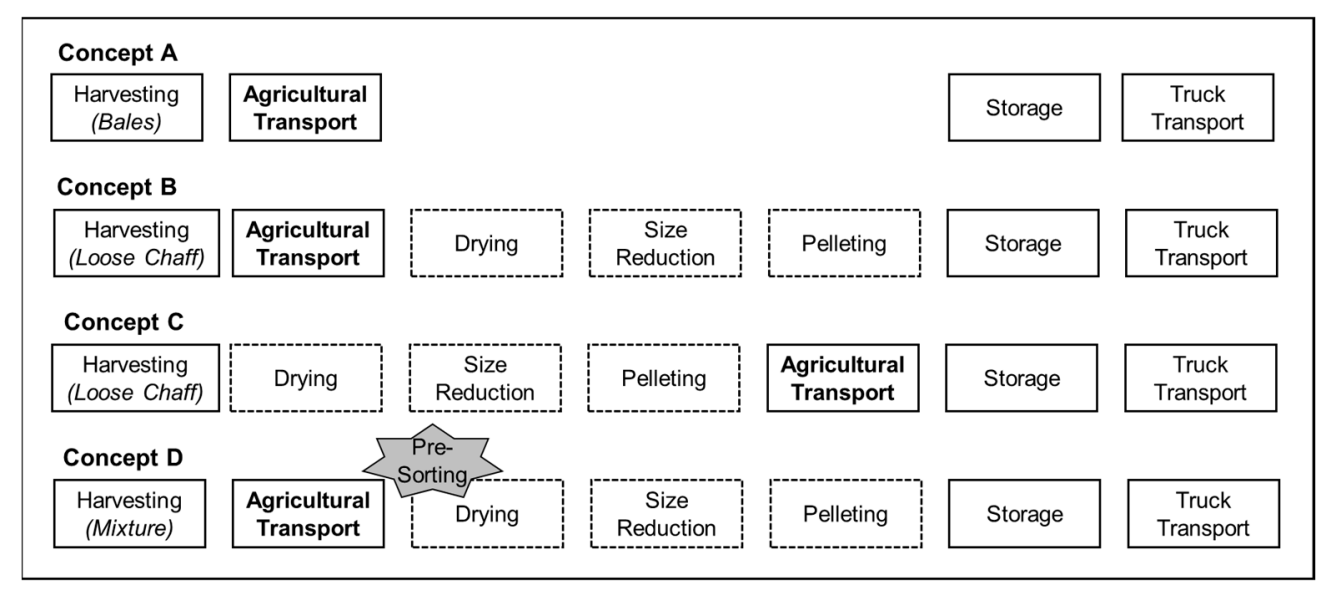

Figure 2. Biomass supply chains of the innovative chaff harvesting concepts proposed by Sweedhart.

For each step of the biomass supply chain, the costs are evaluated per ton of fresh matter to allow the calculation of the total costs. Due to the early stage of the estimate, the data was acquired based on literature values, analogies, expert judgments and offers from suppliers. The costs were calculated defining a base case with set of general assumptions summarized in Table 1. Alterations of these parameters were examined in a sensitivity analysis. 
Table 1. General assumptions for the cost estimation.

\begin{tabular}{cccc}
\hline Parameter & Specification & Concept & Assumption \\
\hline \multirow{2}{*}{ Transport distances } & Field-farm & A, B, C & $2 \mathrm{~km}$ \\
& Field-central plant & D & $16 \mathrm{~km}$ \\
& Further transport & A, B, C, D & $50 \mathrm{~km}$ \\
\hline Performance loss during harvesting & & A, B, C & $18 \%$ \\
\hline Initial moisture chaff & & A, B, C, D & $25 \%(\mathrm{w} / \mathrm{w})$ \\
\hline Capacity utilization & Decentralized plant & B, C & $25 \%$ \\
& Central plant & D & $85 \%$ \\
\hline
\end{tabular}

\subsubsection{Harvesting}

The first step in the supply chain is harvesting and collection of biomass. Sweedhart's harvesting concepts suggest either loading the harvested material directly onto a trailer or placing it on the field requiring subsequent collection. The harvesting costs were calculated with the costs of the required resources based on data from contractor's associations [20-22] and the estimated time effort of the operation. The costs arising from the reduction in harvesting velocity due to the technical adjustment of the combine harvester in Concept A, B and C were allocated to chaff. In Concept D, where grain, straw and chaff are harvested and transported as a mixture, cost allocation is necessary for the transport process. The cost share of chaff and straw was assumed to be $88 \%$ based on the estimated volume shares in the mixture, as the volume and not the weight is the limiting factor in the transport process.

\subsubsection{Agricultural Transport}

The agricultural transport is the transport process, which starts at the field. In this analysis, agricultural transport from the field to the farm is examined, as well as agricultural transport to a central conditioning plant. The distance to the central plant is expected to be longer than to the farm. To calculate the costs, it is assumed that the transport distance includes a round trip, as no return load is available [23]. The transport costs were calculated with the costs of the required resources based on data from Maschinenringen [20-22] and the estimated time effort of the operation. For agricultural transport, tractors with trailers are used. Depending on the transported good, specific trailers like bale trailers or sweep-off carriages were selected for the estimation.

An average transport speed $26 \mathrm{~km} / \mathrm{h}$ for a tractor with a trailer was assumed [24].

\subsubsection{Conditioning}

By the conditioning of biomass, important material characteristics like bulk density, chemical composition and moisture content can be altered. Biomass from plants usually has a low bulk density, which affects transport and storage costs negatively [25]. To increase the specific density, biomass from forest residues, agricultural crop residues or energy plants can be compressed into pellets [25].

Prior research in the Sweedhart project investigated the densification of chaff via pelleting successfully and defined important conditions for the pelleting process [26].

The conditioning operation includes a pelleting process and an additional presorting process in Concept $\mathrm{D}$ due to grain straw and chaff being transported as a mixture. The costs of pelleting were analyzed considering the three major unit operations in a pelleting process: drying, size reduction and densification.

Drying is an individual operation and the process can have various designs [27]. A common approach for drying in an agricultural context is to use potentially existing drying facilities for grain. However, the typical drying in flat stores for grain is probably not feasible for chaff due to the potentially high initial moisture content of up to $40 \%(\mathrm{w} / \mathrm{w})$ [28]. 
Rotary dryers provide a uniform product with high drying rates and are commonly used in biomass drying [25]. Furthermore, they are flexible and applicable for different types of biomass and therefore considered in this analysis $[29,30]$.

The heat energy required for drying the biomass feed is a major cost factor in the pelleting process [25]. The Duval formula (Equation (1)) calculates the moisture withdrawal per unit, which also determines the energy requirement of the dryer [31]. In the equation, $\mathrm{m}_{\text {WaterEvap }}$ represents the mass of the removed moisture and $m_{\text {wet }}$ equals the mass of the wet chaff entering the dryer. $\mathrm{w}_{0}$ is the initial moisture content of chaff and $\mathrm{w}_{1}$ the final moisture content in percent [31].

When herbaceous biomass is pelleted, the moisture content in the pellet press feed must not exceed $\mathrm{w}_{1}=15 \mathrm{w} / \mathrm{w}$ for optimal pelleting results [32].

The heat energy costs of the drying process $\left(\mathrm{UC}_{\text {Heat }}\right)$ are calculated according to Equation (1). based on the moisture withdrawal per unit, the heat energy demand of the dryer $\left(\mathrm{HE}_{\text {Dryer }}\right)$ and the fuel price $\left(\mathrm{C}_{\mathrm{Fuel}}\right)$. The heat demand of the dryer per ton of vaporized water was assumed with $\mathrm{HE}_{\text {Dryer }}=1000 \mathrm{kWh} / \mathrm{t}$ of evaporated water [33].

$$
\begin{gathered}
\mathrm{m}_{\text {WaterEvap }}=\mathrm{m}_{\text {wet }} \times \frac{\mathrm{w}_{0}-\mathrm{w}_{1}}{100 \%-\mathrm{w}_{1}} \\
U C_{\text {Heat }}=m_{\text {WaterEvap }} \times H E_{\text {Dryer }} \times C_{\text {Fuel }}
\end{gathered}
$$

A pellet press can process fibers between 3.2 and $6.4 \mathrm{~mm}$ [34]. Therefore, a reduction in size is necessary, before feeding chaff into the press [26]. In biomass pelleting plants, hammer mills are commonly used for grinding [25]. Therefore, the application of a hammer mill in the pelleting process of chaff was set in this analysis.

After the size reduction unit, the pellet press compacts the biomass into pellets. Apart from stationary pelleting plants, mobile pelleting is an option to compact biomass. Technologies for the mobile pelleting of straw and other biomass fractions are already available on the market [35]. Self-propelled pellet harvesters produce pellets in one single operation by picking up biomass from the swath for compacting. Other manufacturers offer mobile plants pulled by a tractor for pelleting by the field side $[36,37]$.

The company PCM Green Energy developed a pelleting plant that fits onto a truck and that has a throughput of $1-1.5 \mathrm{t} / \mathrm{h}$. This mobile pelleting plant can process various biomass feeds including husks and straw [32]. Therefore, it can be expected that chaff can be processed as well. Regarding this plant, the production rate in the decentralized pelleting process has been chosen with $1 \mathrm{t} / \mathrm{h}$. The production rate of the central plant was assumed to be $3 \mathrm{t} / \mathrm{h}$.

The capacity utilization of the pelleting plant has a high impact on the costs of the conditioning process. While calculations for stationary plants consider capacity utilization of $85 \%$ to $90 \%$, mobile plants have lower utilization [25,33]. According to Neumann (2015), contractors require a capacity utilization of at least $25 \%$ to run a mobile pelleting plant economically [38]. This analysis assumed a capacity utilization of $25 \%$ in the decentralized plant and $85 \%$ in the central plant.

\subsubsection{Storage}

Chaff is a seasonal product that is harvested once a year. The harvest periods of chaff and straw are linked to the ripening of grain, which is harvested between July and September. To ensure a continuous supply of biomass to the end user, the time between harvest and utilization needs to be bridged. Storage is therefore necessary to ensure a continuous supply over the whole year [39].

The storage costs were calculated as the sum of the costs for building and operating the storage facility. The biomass must be transferred to the stock and loaded again for further transport [39]. In addition, some authors consider material loss due to degradation of biomass [23,40]. A monthly degradation rate of $0.5 \%$ was adopted in this analysis [23]. 
In principle, biomass storage can occur at the farm, at the end use (e.g., the combustion plant), or at an intermediate storage facility. Due to potential space limitations storage at a combustion plant is not considered [39]. This analysis examines storage at the farm in Concept A, B, and C and an intermediate storage at a central conditioning plant in Concept D.

\subsubsection{Further Transport}

In this analysis, an additional transport process by truck from the storage facility to the application site is considered. The transport costs are not only affected by the transport distance, but also by the transport speed. The average transport speed is assumed to be $60 \mathrm{~km} / \mathrm{h} \mathrm{[41].} \mathrm{The} \mathrm{hourly} \mathrm{costs} \mathrm{of} \mathrm{the}$ required resources are estimated based on data from contractor's associations [21].

\subsection{Cost Estimation Methods}

The cost estimation of the innovative harvesting concepts takes place at an early stage of project definition. Currently, there are no established harvesting concepts for chaff and the target of the cost estimation is to evaluate the general feasibility of the concepts. The applied methods are therefore analogies to similar processes, estimation factor rules, judgment from experts and assumptions. The cost estimation in this thesis goes beyond the conceptual stage, defining the main items of the equipment and their capacity. According to the cost estimation classes defined by the AACE International Recommended Practice No. 18 R-97, the estimate accuracy is expected to range between -30 and $+50 \%$, which is typical for the fourth cost estimate class [42].

Chaff and straw are byproducts of the grain harvest. Calculations of straw recovery costs usually consider only the additional costs caused by straw [43]. The costs of the combine harvester are allocated to the main product grain. The same approach was chosen in this analysis to estimate the costs of chaff supply by considering only the additional costs of chaff. For the cost calculation, the full costing method was applied to include fixed costs. According to the VDI guideline 2067 part 1, costs based on capital, energy, personnel and other costs were considered.

The annual capital costs $U C_{\text {Inv }}$ were calculated according to Equation (3). The capital recovery factor e converts the total capital costs of the investment over the lifetime into equal annual values of costs [25]. $\operatorname{Inv}_{\mathrm{Eq}}$ are the investment costs of the equipment and Prod ${ }_{\mathrm{Annual}}$ equals the annual production in tons. In the base case, an annual production of 2190 ton was estimated for the decentralized plant and 22,338 tons for the central plant.

$$
\mathrm{UC}_{\mathrm{Inv}}=\frac{\sum \mathrm{e} \times \operatorname{Inv}_{\mathrm{Eq}}}{\text { Prod }_{\text {Annual }}}
$$

The capital recovery factor is calculated based on the interest rate $i$, according to Equation (4) [25]. In this paper, an interest rate of $7 \%$ is assumed. The utilization period $\mathrm{n}$ is selected based on data from previous analyses $[23,33]$, ranging between 10 and 20 years.

$$
\mathrm{e}=\frac{\mathrm{i}(1+\mathrm{i})^{\mathrm{n}}}{(1+\mathrm{i})^{\mathrm{n}}-1}
$$

If the costs are not available for a specific capacity, a capacity factor rule was applied. A generally approved capacity factor rule is the rule of two thirds, which describes the relationship between costs and capacity. Capacity factor rules take into account that the specific costs follow the economy of scale. An increase in capacity leads to a non-proportional increase in investment costs, reducing the specific costs (Equation (5)) [44].

$$
\frac{\operatorname{Inv}_{\mathrm{Eq}, 1}}{\operatorname{Inv}_{\mathrm{Eq}, 0}}=\left(\frac{\operatorname{Prod}_{\text {Rate, },}}{\operatorname{Prod}_{\text {Rate }, 0}}\right)^{\alpha}
$$


$\operatorname{Prod}_{\text {Rate }, 1}$ and Prod Rate, 0 are the production capacities of the equipment. $\operatorname{Inv}_{\mathrm{Eq}, 1}$ and $\operatorname{Inv}_{\mathrm{Eq}, 0}$ describe the investment costs. The costs $\operatorname{Inv}_{\mathrm{Eq}, 0}$ and production rate Prod $\operatorname{Rate}, 0_{0}$ are taken from [33]. $\operatorname{Inv}_{\mathrm{Eq}, 1}$ were calculated according to Equation (5). As a thumb rule, the extrapolation factor $\alpha$ is 0.6. For detailed calculations, the factor can be adjusted according to the equipment [45].

The maintenance unit costs were calculated in percent of the investment costs and evenly spread over the whole utilization period. The electricity costs were estimated by multiplying the rated power of the equipment with the operating hours and the price of electricity. The costs of drying were estimated considering the heat energy demand for drying and the gas price. Calculations of personnel costs consider a share of variable costs and a share of fixed costs. The variable share of the personnel costs was calculated by multiplying the number of people, the hourly personnel rate and the operating hours. In addition, fixed costs were considered for administration and marketing [33]. Other costs comprise of insurance rates, general levies, taxes and costs of administration [46]. They were calculated as a percentage of the investment costs [33].

The data has been taken primarily from recent articles and books. As there is no information published on the costs of chaff supply at the time, analogies to similar products were used. Data is available on the provision costs of woody biomass and herbaceous biomass in general. Conditioning operations and production costs of wood pellets under European conditions were examined in a previous analysis based on a full costing method [33]. From this study, the investment costs of the pelleting plant, the maintenance percentage and the fixed share of the personnel costs were obtained.

The costs of agricultural operations like harvesting and transport were examined based on price suggestions for contractors. Contractors associations ("Maschinenringe"), joined by many farmers in Germany, publish price suggestions for agricultural operations [47]. The price suggestions were selected including the full costs of the operation per hour (including personnel and energy costs) considering data from three different associations [20-22]. With the output and the required time effort, the costs per ton were calculated.

\subsection{Sensitivity Analysis}

The costs of chaff supply were calculated along the steps of the biomass supply chain, resulting in a single value of total costs for each concept. As the accuracy of early cost estimates varies in a broad range, the impact of the general assumptions in the base case (Table 1) was analyzed in a sensitivity analysis by means of tornado diagrams. Tornado diagrams plot the effect on the dependent variable, when all independent variables are changed by the same percentage. The independent variable with the strongest impact is depicted at the top, followed by the other independent variables with decreasing relevance [44]. Thereby the variable with the strongest impact was determined.

\section{Results}

\subsection{Chaff Supply Costs}

Table 2 shows the costs for each concept along the biomass supply chain and summarizes the total costs.

Table 2. Costs of chaff supply along the steps of the biomass supply chain.

\begin{tabular}{ccccccc}
\hline Concept & Harvesting & Agricultural Transport & Condi-Tioning & Storage & Further Transport & Total Costs \\
\hline A $\left[€ / t^{*}\right]$ & 30.17 & 6.14 & & 16.93 & 15.02 & $\mathbf{6 2 . 9 4}$ \\
B $\left[€ / t^{* *}\right]$ & 44.95 & 9.79 & 136.42 & 12.62 & 4.76 & $\mathbf{2 0 8 . 5 3}$ \\
C [€/t* $\left.t^{* *}\right]$ & 44.95 & 0.55 & 136.42 & 12.35 & 4.76 & $\mathbf{1 9 9 . 0 2}$ \\
$\mathbf{D}\left[€ / \mathbf{t}^{* *}\right]$ & 8.54 & 10.51 & 51.45 & 9.00 & 4.76 & $\mathbf{8 4 . 2 5}$ \\
\hline \multicolumn{5}{r}{${ }^{*}$ chaff_straw; ${ }^{* *}$ chaff. }
\end{tabular}


The production of chaff-straw bales (Concept A) leads to the lowest overall costs, followed by harvesting without fractioning (Concept $\mathrm{D}$ ). The highest total costs originate from collecting chaff as a single fraction, suggested by Concept B and C. Table 2 allows the comparison of the concepts in the discrete steps of the biomass supply chain. The harvesting costs are significantly reduced by harvesting without fractioning compared to producing bales or collecting loose chaff. The cost-saving originates primarily from a reduction in the number of processes while the harvesting velocity remains unchanged.

The costs of agricultural transport mainly depend on the material density and the transport distance. The agricultural transport of chaff pellets, suggested by Concept $C$, is therefore the most economical option.

Table 2 reveals that the conditioning process has a major cost share in all concepts that consider pelleting chaff. A substantial cost saving is achieved, if the conditioning operation takes places at a central plant, according to Concept D. By changing the supply chain, the cost reduction potential could be exploited in Concept B as well. If the material was conditioned in a central plant, the costs for conditioning would decrease to $51.45 € / t_{\text {chaff }}$ (Table 2). Although the costs of agricultural transport would then increase to $78.28 € / t_{\text {chaff }}$ due to the longer distance and the low density of loose chaff, the total costs were reduced by around $17 € / t_{\text {chaff. }}$. This indicates that by adapting the concepts to the prevailing conditions, cost reduction potentials can be exploited.

According to Table 2, Concept A has the highest storage costs. This originates from chaff-straw bales having a lower density than pellets, therefore requiring a larger storage facility. The storage costs for pellets vary across Concept $B, C$ and D, due to different previous costs considered in the calculation of the material loss.

The costs for further transport are the same for all concepts, except for Concept A. Again, the lower density of the bales causes higher costs.

Comparing the total costs of the supply chains, Concept D provides chaff pellets with the lowest costs. Concept A has the lowest total cost but produces chaff-straw bales instead of pellets.

\subsection{Sensitivity Analysis}

To determine the impact of assumptions made in the base case, tornado diagrams were calculated by varying the parameter by $+/-20 \%$ of the initial value. One tornado diagram was calculated for each concept, given in Figure 3.

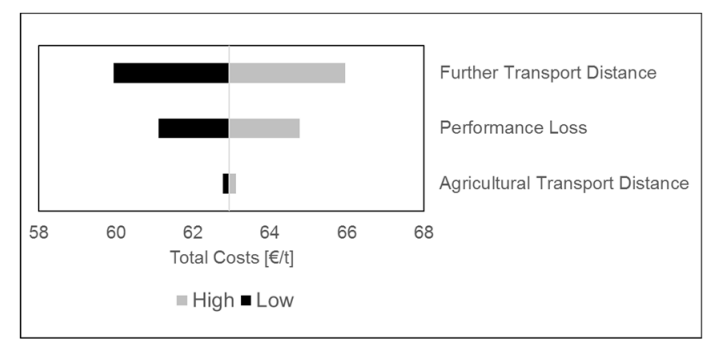

(A)

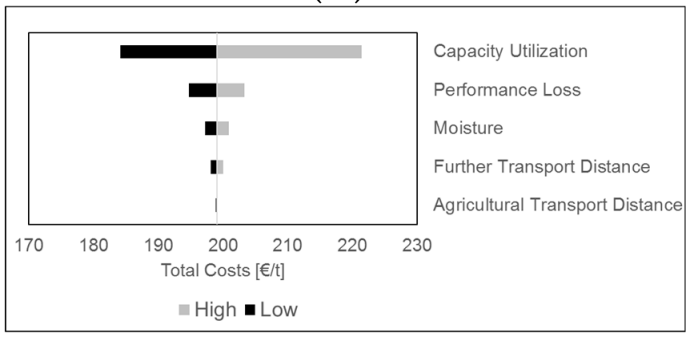

(C)

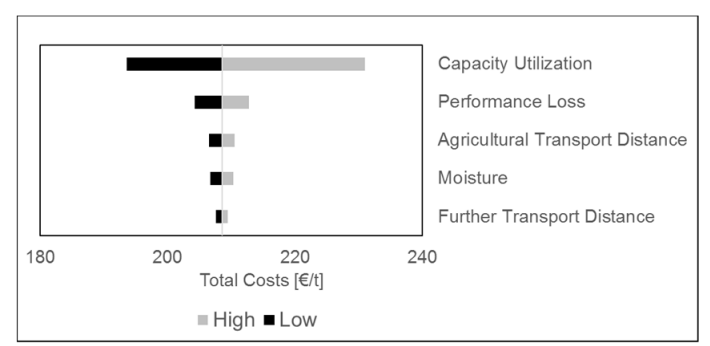

(B)

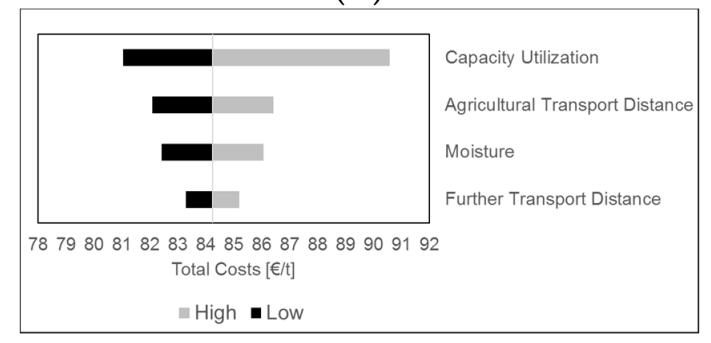

(D)

Figure 3. (A) Tornado Diagram Concept A (B) Tornado Diagram Concept B. (C) Tornado Diagram Concept C, (D) Tornado Diagram Concept D. 
Figure 3 shows that the capacity utilization of the pelleting process has the strongest impact on the total costs. The performance loss of the combine harvester, which decreases the harvesting velocity in Concept A, B, and C, is the second most important parameter. The total costs of chaff supply are also sensitive to the moisture content of the material, which increases the drying costs linearly. Additionally, the highly variable transport distances influence the total costs.

The tornado diagrams indicate that the capacity utilization has the strongest influence on the total costs. Therefore, the parameter was analyzed in more detail. Figure 4 depicts the conditioning costs over the capacity utilization from $20 \%$ to $100 \%$. According to the slope of the graphs, a capacity utilization below around $60 \%$ is unfavorable due to an exponential increase in the total costs. In addition, the calculation reveals that the large difference in conditioning costs for Concept $B$ and $C$ compared to concept $\mathrm{D}$ is primarily caused by assuming different capacity utilization in the base case. The remaining difference in conditioning costs results from different production rates as well as including a presorting step in case of central conditioning (Concept D).

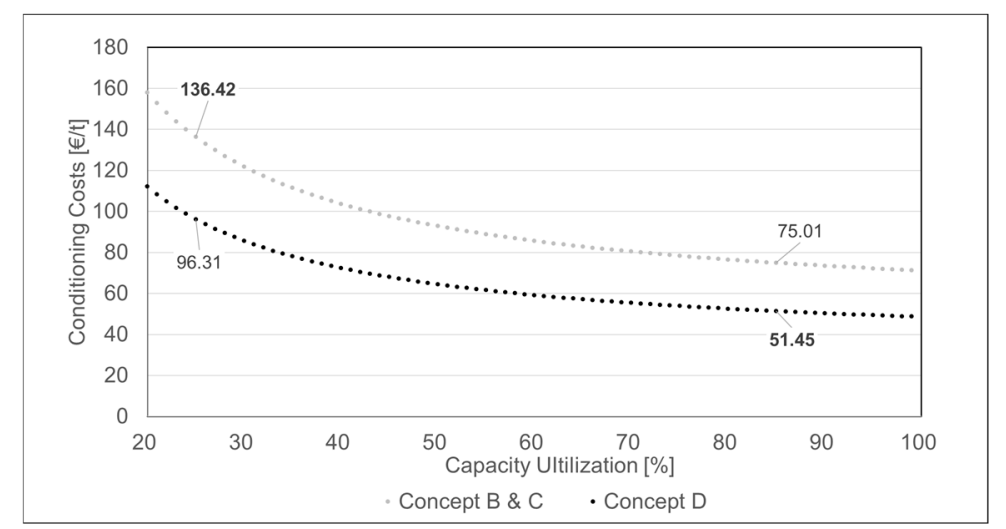

Figure 4 . Sensitivity of conditioning costs regarding capacity utilization between $20 \%$ and $99 \%$.

The sensitivity analysis reveals that the total chaff supply costs of the suggested concepts depend strongly on the prevailing conditions. In reality, the range in which the parameters vary is different to the range examined in the tornado diagrams. By adjusting the parameters to a test region, the accuracy of the estimate could be increased.

\section{Discussion}

\subsection{Economic Efficiency}

This analysis determines solely the costs of accessing the harvest residue chaff as a potential biomass feedstock. If a supply of chaff is economically feasible also depends on the revenues that can be generated by a utilization. For agricultural biomass, energetic application i.e. the utilization as biogas or in combustion plants is possible in principle. Combustion applications of chaff have been examined in prior research based on the assumption that chaff can contribute to the renewable energy supply [26]. In addition, the application as a biogas substrate is possible in theory, applying the results of straw pellet digestion to chaff [48].

Potential material applications for chaff are animal husbandry, utilization as fiber raw material and extraction of natural ingredients in biochemistry applications [13].

Table 3 gives the market prices for similar products indicating potential revenues for chaff. 
Table 3. Overview of potential revenues.

\begin{tabular}{ccccc}
\hline Application & & Reference Product & Revenues & Reference \\
\hline \multirow{3}{*}{ Pellets } & Combustion & Wood pellets & $140 € / \mathrm{t}$ & {$[49]$} \\
& Biogas & Corn silage & $90 € / \mathrm{t}$ & {$[48]$} \\
\multirow{2}{*}{ Bales } & Animal bedding & Straw pellets & $200 € / \mathrm{t}$ & {$[50]$} \\
& Animal bedding, combustion & Straw bales & $81 € / \mathrm{t}$ & {$[51]$} \\
\hline
\end{tabular}

The overview shows that revenues for chaff pellets are higher than for bales. Among the considered alternatives, the application of chaff pellets in animal bedding promises the highest revenues. Energetic application via combustion is the second-best option, a utilization as biogas feed generates the lowest revenues.

Pelleted chaff for animal bedding appears to be the superior application pathway. In this context, it is important to consider that the actual profit that can be gained decreases as the equilibrium price falls, if large amounts of a new product are supplied to the currently evolving market of pelleted bedding material [52]. Chaff pellets can also be used for combustion applications to serve the biomass fuel market, which has a large market volume and where new resources are required [53].

Figure 5 compares the total costs and potential revenues. According to the figure, the best option is harvesting without fractioning for the application in animal bedding. Pellets produced according to Concept $\mathrm{D}$ could also be combusted with revenues exceeding the costs substantially. The application as biogas feedstock is the least favorable option as the revenues exceed the costs only by about $5 € / t$. The implementation of Concept $\mathrm{B}$ or $\mathrm{C}$ is not recommended from an economic point of view as the costs of Concept $B$ exceed the revenues of each application. Implementing Concept $C$ could solely cover the costs if the pellets are applied in animal bedding. The production of chaff-straw bales according to Concept $\mathrm{A}$ appears economically feasible as the potential revenues exceed the costs by about $18 € / \mathrm{t}$.

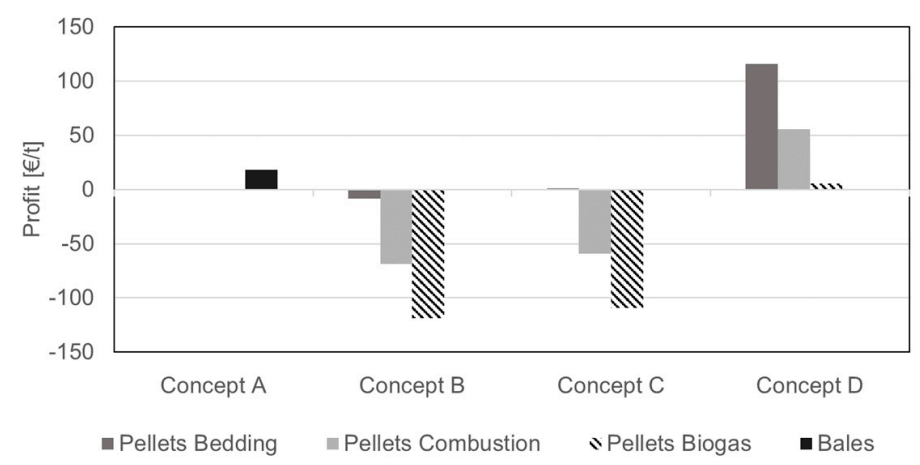

Figure 5. Difference potential revenues and total costs of chaff supply.

\subsection{Estimate Accuracy}

As this analysis assesses the costs of chaff supply under general framework conditions, the methods selected for the estimation are analogies, estimations, expert judgment, and offers from suppliers. Due to the early stage of the estimate, the costs of chaff supply are not directly measured, thus limiting the accuracy of the calculation.

There is no data available for the costs of the whole chaff supply chain, but conditioning costs of biomass were analyzed in previous studies. The costs determined for the central conditioning operation can be compared to an in depth-evaluation of wood pelleting costs under Austrian conditions [33]. The central conditioning costs vary from this study (raw material excluded) by $11.3 \%$. Many framework conditions are identical in this analysis like production rate, investment costs of equipment and rated power. However, the prices of electricity and gas have been adjusted and the moisture content of the raw material differs. Although the results are therefore not directly comparable, the cost range is similar. 
The costs of decentralized conditioning can be compared to price suggestions for pelleting straw with a mobile plant in Germany. However, these mobile plants do not include a drying operation, which was considered to process chaff. In Germany, pelleting with a mobile plant costs between $75 € / t$ and $120 € / t$ with additional costs for maintenance [38]. The costs are at the upper end of the range, if the feed requires size reduction with the hammer mill. The costs variation is with $13.7 \%$ in an anticipated range.

\subsection{Applicability}

Many framework conditions have been defined during the development process of the base case. As the individual conditions of a farm or region cannot be covered by a general base case, the presented chaff supply costs are not directly applicable to an individual farm. This would require a detailed analysis of the unique conditions and an adaption of the relevant factors, keeping in mind that the prices for agricultural goods vary over the year, the costs for agricultural operations differ depending on the contractor's association and the annual yield fluctuates.

The sensitivity analysis revealed that some of the assumptions made in the base case have a major impact on the chaff supply costs. The economic effectiveness of the concepts is therefore very sensitive to the choice of these parameters. Especially the performance loss of the combine harvester and the capacity utilization of the conditioning plant have a high impact on the total costs of the other concepts.

This work evaluates the harvesting concepts with respect to the economic efficiency. If the harvesting concepts are implemented with the prior motive of weed management, the preferability of the concepts can shift. This is more relevant for Australian and North-American conditions, where herbicide resistant weeds are a major problem in agriculture [9].

The analysis of the biomass supply chain in discrete steps shows that there are numerous possibilities and combinations of processes to supply biomass to the end user. The overall objective of an integrated and optimized biomass supply chain is to find the cost-optimal combination of processes.

\section{Conclusions}

This analysis concludes that it can be economically feasible to utilize the harvest residue chaff and thereby exploit an unused feedstock. The four examined harvesting concepts differ severely in the economic efficiency. In general, it can be derived that separating the products and supplying them with individual chains leads to higher costs. In line with that, the cost analysis revealed that harvesting a mixture of grain, straw, and chaff according to Concept D leads to a major cost reduction of the harvesting process. The cost saving effect is based on a reduction in agricultural operations and a central conditioning process that decreases the fixed costs. Due to the extensive adaption of technologies and process chains, the implementation of Concept $\mathrm{D}$ is complex.

Further research should focus on adjusting the estimation to a test region to evaluate the costs and revenues for the prevailing conditions and identify cost-saving potentials. This includes a thorough analysis of the regional chaff potential and an assessment of the availability of other raw materials that can be processed in the pelleting plant. Determining a test region also allows the adaption of the transport distances to the actual conditions. For an economic evaluation, it is also necessary to investigate the application pathways of chaff and their potential revenues in detail.

Future research is also necessary to assess the ecological effects of the suggested harvesting concepts addressing important issues like, energy consumption and carbon dioxide emissions and soil compaction.

Author Contributions: C.G. was responsible for the conceptualization of the investigated concepts. J.S.U. and C.G. defined the methodology and the influencing factors that should be included in the analysis. J.S.U. was responsible for data collection, for the formal analysis and the sensitivity analysis. C.G. coordinated the project Sweedhart and supervised J.S.U. in preparing the first work. J.S.U. wrote the first draft of the manuscript including all figures and tables. All authors reviewed and accepted the manuscript. 
Funding: This work was done as a part of the project Sweedhart-Separation of weeds during harvesting and hygienisation to enhance biomass production in the long term. Sweedhart is a transnational research project funded in the frame of the ERA-NET Cofund FACCE SURPLUS (Sustainable and Resilient agriculture for food and non-food systems), which is formed in collaboration between the European Commission and a partnership of 15 countries in the frame of the Joint Programming Initiative on Agriculture, Food Security and Climate Change (FACCE-JPI). FACCE SURPLUS is committed to improve collaboration across the European Research Area in the range of diverse, but integrated, food and non-food biomass production and transformation systems, including biorefining. We thank the German Federal Ministry of Education and Research (project number 031B0164A) for financial support at national level. The responsibility for the contents of this publication is taken fully by the authors.

Conflicts of Interest: The authors declare no conflict of interest. The funders had no role in the design of the study; in the collection, analyses, or interpretation of data; in the writing of the manuscript, or in the decision to publish the results.

\section{References}

1. Weiser, C.; Zeller, V.; Reinicke, F.; Wagner, B.; Majer, S.; Vetter, A.; Thraen, D. Integrated assessment of sustainable cereal straw potential and different straw-based energy applications in Germany. Appl. Energy 2014, 114, 749-762. [CrossRef]

2. Mateos, E. Study on the Potential of Forest Biomass Residues for Bio-Energy. Proceedings 2018, $2,1420$. [CrossRef]

3. Panwar, V.; Prasad, B.; Wasewar, K.L. Biomass Residue Briquetting and Characterization. J. Energy Eng. 2011, 137, 108-114. [CrossRef]

4. Avcıoğlu, A.O.; Dayığlu, M.A.; Türker, U. Assessment of the energy potential of agricultural biomass residues in Turkey. Renew. Energy 2019, 138, 610-619. [CrossRef]

5. 36th Regulation for the Implementation of the Federal-Immision Protection. Regulation for the Implementation of the Regulations for the Contingent of Biofuels. Available online: http://www.gesetze-iminternet.de/bimschv_36/(accessed on 18 September 2019).

6. Miu, P. Combine Harvesters: Theory, Modeling, and Design; CRC Press: Boca Raton, FL, USA, 2015; pp. 1-54. ISBN 9781138748279.

7. Glasner, C.; Vieregge, C.; Robert, J.; Fenselau, J.; Bitarafan, Z.; Andreasen, C. Evaluation of New Harvesting Methods to Reduce Weeds on Arable Fields and Collect a New Feedstock. Energies 2019, 12, 1688. [CrossRef]

8. Shirtliffe, S.J.; Entz, M.H. Chaff collection reduces seed dispersal of wild oat (Avena fatua) by a combine harvester. Weed sci. 2005, 53, 465-470. [CrossRef]

9. Heap, I. The International Survey of Herbicide Resistant Weeds. Available online: http://www.weedscience. org/Summary/CountrySummary.aspx (accessed on 22 March 2019).

10. Anon. European Parliament Resolution of 13 September 2018 on the Implementation of the Plant Protection Products Regulation (EC) No 1107/2009 (2017/2128(INI)). Available online: http://www.europarl.europa.eu/ (accessed on 18 September 2019).

11. EUROSTAT. Wheat and Spelt by Area, Production and Humidity. Available online: http://ec. europa.eu/eurostat/tgm/table.do?tab=table\&init=1\&language=en\&pcode=tag00047\&plugin=1 (accessed on 18 November 2018).

12. Glasner, C.; Andreasen, C.; Vieregge, C.; Dikiy, A.; Fenselau, J.; Bitarafan, Z.; Shumilina, E. Adaptions of Harvesting Methods and Concepts in order to Reduce Weeds on Agricultural Fields and to Gain Potentially a So Far Unexploited Biomass Feedstock. Eur. Biomass Conf. Exhib. Proc. 2018, 2018, 64-70. [CrossRef]

13. Rumpler, J. Wertschöpfungsmöglichkeiten und Marktpotenziale für die Ernteprodukte Spreu, Stroh und SpreuStroh bei der Nutzung als landwirtschaftliche Reststoff-Biomasse. Available online: https://lig.sachsen-anhalt.de/fileadmin/Bibliothek/Politik_und_Verwaltung/MLU/LLFG/Dokumente/04_ themen/technik/2017_Studie_Wertschoepfung.pdf (accessed on 3 January 2018).

14. Croker, K.; Watt, P. The Good Food Guide for Sheep: Feeding Sheep for Meat Production in the Areas of Western Australia. Available online: https://researchlibrary.agric.wa.gov.au/cgi/viewcontent.cgi?article= 1177\&context=bulletins (accessed on 4 January 2019).

15. Hutton, G. Increasing Cow/Calf Profitability Using Chaff and Chaff/Straw Feedstuffs. Available online: https://www1.agric.gov.ab.ca/\$department/deptdocs.nsf/all/agdex1156 (accessed on 9 January 2019). 
16. Esmail, A.; Tawfik, M. The Concept of Sustainable Architecture and Urbanization in Dakhla and Kharga Oases in Egypt. WIT Trans. Build Environ. 2016, 159, 61-71. [CrossRef]

17. Rudolph, W. Mit der Kompakternte neue Wege der Vermarktung öffnen. Bauernzeitung 2016, 40, 10-13.

18. Rumpler, J.; Beneke, F. Harvest All at Once. Available online: https://www.researchgate.net/publication/ 281120054_Harvest_all_at_once (accessed on 20 November 2018).

19. Rumpler, J.; Beneke, F. Pragmatists Required! Available online: https://www.researchgate.net/publication/ 281120264_Pragmatists_required (accessed on 17 October 2018).

20. MR Laufen. Verrechnungssätze 2017. Available online: https://www.mrlaufen.de/images/bilder/ verrechnungssaetze/2017/verrechnungssaetze_2017_a6_quer_4c.pdf (accessed on 11 October 2018).

21. MR Stade. Verrechnungssätze Maschinenring Stade 2018. Available online: http://www.maschinenringstade.de/index.php/download.html?file=files/mr/ (accessed on 10 January 2019).

22. LWK NRW. Erfahrungssätze für Maschinenring-Arbeiten unter Landwirten. Available online: https: //www.landwirtschaftskammer.de/landwirtschaft/beratung/pdf/erfahrungssaetze-wl.pdf (accessed on 11 October 2018).

23. Rentizelas, A.A.; Tolis, A.J.; Tatsiopoulos, I.P. Logistics issues of biomass: The storage problem and the multi-biomass supply chain. Renew. Sustain. Energy Rev. 2009, 13, 887-894. [CrossRef]

24. Herrmann, A.; Pickel, P.; Fröba, N. Transportgeschwindigkeit von Traktoren: Auswirkung unterschiedlicher bauartbedingter Höchstgeschwindigkeiten. Landtechnik 2000, 55, 338-339.

25. Mani, S.; Sokhansanj, S.; Bi, X.; Turhollow, A. Economics of producing fuel pellets from biomass. Appl. Eng. Agric. 2006, 22, 421-426. [CrossRef]

26. Weiß, B.D.; Glasner, C. Evaluation of the Process Steps of Pretreatment, Pellet Production and Combustion for an Energetic Utilization of Wheat Chaff. Front. Environ. Sci. 2018, 6, 1313. [CrossRef]

27. Mujumdar, A.S. Handbook of Industrial Drying, 4th ed.; CRC Press: Boca Raton, FL, USA, 2015; ISBN 9781466596658.

28. DLG e. V. Getreide Sicher lagern: Reinigen, Trocknen und Kühlen. Available online: https://www.dlg.org/ fileadmin/downloads/merkblaetter/dlg-merkblatt_425.pdf (accessed on 15 January 2019).

29. Amos, W. Report on Biomass Drying Technology. Available online: https://www.nrel.gov/docs/fy99osti/ 25885.pdf (accessed on 24 October 2018).

30. Mujumdar, A.S. Classification and Selection of Industrial Dryers. Available online: https://www.researchgate. net/publication/265533511_CLASSIFICATION_AND_SELECTION_OF_INDUSTRIAL_DRYERS (accessed on 28 November 2018).

31. Grube, J.; Böckelmann, M. The harvest home and dry-Key figures for grain drying. Landtechnik 2011, 66, 276-280.

32. PCM Green Energy. Pelletieranlage. Available online: https://www.pcm-greenenergy.de/de/pelletieranlage/ (accessed on 17 January 2019).

33. Thek, G.; Obernberger, I. Wood pellet production costs under Austrian and in comparison to Swedish framework conditions. Biomass Bioenergy 2004, 27, 671-693. [CrossRef]

34. PCM Green Energy. Technische Daten. Available online: https:/www.pcm-greenenergy.de/de/ pelletieranlage/\#toggle-id-5 (accessed on 17 January 2019).

35. Kaltschmitt, M.; Hartmann, H.; Hofbauer, H. Energie aus Biomasse. Grundlagen, Techniken und Verfahren, 3rd ed.; Aktualisierte und Erweiterte Auflage; Springer Vieweg: Berlin/Heidelberg, Germany, 2016; ISBN 978-3-662-47437-2.

36. Schaider Pelletech. So Arbeitet Schaider Pelletec D 8.0. Available online: http://www.schaider-group.com/ media/folder_pelletec_d.pdf (accessed on 17 January 2019).

37. KRONE. Premos 5000 Mobiler Pellet-Vollernter. Available online: https://landmaschinen.krone.de/english/ products/pellet-harvester/premos-5000/ (accessed on 17 January 2019).

38. Neumann, H. Pelletierung auf Rädern. Eilbote 2015, 23, 10-14.

39. Ortiz, D.S.; Curtright, A.E.; Samaras, C.; Litovitz, A.; Burger, N. Near-Term Opportunities for Integrating Biomass into the U.S. Electricity Supply. Technical Considerations; Rand: Santa Monica, CA, USA, 2011; ISBN 978-0-8330-5835-5.

40. Sokhansanj, S.; Turhollow, A.; Wilkerson, E. Development of the Integrated Biomass Supply Analysis and Logistics Model (IBSAL); Oak Ridge National Laboratory: Oak Ridge, TN, USA, 2008; ORNL/TM-2006/57. 
41. Liguori, P. Analysis: China-Europe Rail Growth Belies EU Rail Challenges. Available online: https://www.joc.com/rail-intermodal/international-rail/analysis-europe-wide-rail-freight-would-be-procommerce-green_20180226.html (accessed on 11 January 2019).

42. AACE International. Cost Estimate Classification System-As Applied in Engineering, Procurement, and Construction for the Process Industries; AACE International Recommended Practice No. 18R-97; AACE Inc.: Morgantown, WV, USA, 2011.

43. Degner, J. Kosten und Arbeitsaufwand der Strohbergung mit Quaderballenpresse bei Feldrandfreilagerung. Available online: http://www.tll.de/www/daten/publikationen/richtwerte/stro0907.pdf (accessed on 13 February 2019).

44. Crundwell, F.K. Finance for Engineers: Evaluation and Funding of Capital Projects; Springer: London, UK, 2008; ISBN 978-1-84800-032-2.

45. Valentas, K.J. Handbook of Food Engineering Practice; CRC Press: Boca Raton, FL, USA, 1997; ISBN 9780849386947.

46. Wirtschaftlichkeit gebäudetechnischer Anlagen—Grundlagen und Kostenberechnung; VDI 2067 Blatt 1: 2012-09; Beuth-Verlag: Berlin, Germany, 2012.

47. Wesenberg, M. Die Mähdrusch-Kosten sind enorm gestiegen: Lohnunternehmer müssen scharf kalkulieren. Landwirtschaftliches Wochenblatt 2015, 24, 15-16.

48. Schwarz, B. Strohbasierte Biogaspellets als Alternatives Inputsubstrat in Biogasanlagen: Fachtagung "Biogas aus Stroh", 30.08.2016 in Heiden. Available online: https://docplayer.org/78090440-Strohbasiertebiogaspellets-als-alternatives-inputsubstrat-in-biogasanlagen.html (accessed on 4 January 2019).

49. RBCN. Rotterdam Biomass Commodities Network. BiomassMarket Update. Available online: https: //rbcn.nl/wp-content/uploads/bsk-pdf-/2018/01/2018-Q1-RBCN-BMU.pdf (accessed on 1 February 2019).

50. Paligo. Strohgranulat Einstreu. Available online: https://www.paligo.de/tierbedarf/tiereinstreu/ strohgranulat-einstreu/ (accessed on 6 January 2019).

51. agrarheute. Strohpreise: Soviel kostet der Großballen. Available online: https://www.agrarheute.com/ pflanze/strohpreise-soviel-kostet-grossballen-441423 (accessed on 28 February 2019).

52. Dwivedi, D.N. Microeconomics: Theory and Applications; Pearson Education: New Delhi, India, 2006; ISBN 8177586483.

53. Zwart, R.; de Boe, M. Market Analysis for the Start of a Biomass Commodities Exchange. Available online: http://www.biomassconsultancy.com/Publications/Market\%20Analysis\%20Biomass\% 20Commodities\%20Exchange\%20August\%202010.pdf (accessed on 1 February 2019).

(C) 2019 by the authors. Licensee MDPI, Basel, Switzerland. This article is an open access article distributed under the terms and conditions of the Creative Commons Attribution (CC BY) license (http://creativecommons.org/licenses/by/4.0/). 